\title{
Phytochemical analysis and in vitro free radical scavenging activity of rhizome of Zingiber officinale Rosc.
}

\author{
P. Manju and A. Pushpa* \\ Department of Biochemistry, Rathnavel Subramaniam College of Arts and Science, Coimbatore-641402, Tamil Nadu, India. \\ *Department of Biochemistry, Biotechnology and Bioinformatics, Avinashilingam Institute for Home Science and Higher Education for \\ Women, Coimbatore-641043, Tamil Nadu, India
}

\section{Article Info}

Article history

Received 11 September 2020

Revised 28 October 2020

Accepted 30 October 2020

Published online 30 December 2020

\section{Keywords}

Zingiber officinale Rosc.

Herb

Antioxidants

Free radical scavenging

Ascorbic acid

Rhizome

\begin{abstract}
Zingiber officinale Rosc. belongs to the family, Zingiberaceae used extensively as a spice, flavouring agent and herbal remedy. The rhizome of the plant is known for its medicinal, nutritional and tradional values. The present study was conducted to elucidate the phytochemical constituents of crude methanolic extract of rhizome of $Z$. officinale and analyse the free radical scavenging activity. Phytochemical screening was done by standard test indicative of characteristic colour changes, using standard phytochemical reaction methods. Free radical scavenging activity was determined by DPPH assay, superoxide scavenging assay, nitric oxide scavenging assay and hydrogen peroxide scavenging assay. The results of the preliminary phytochemical screening of the methanolic extract of $Z$. officinale (ZoMe) revealed the presence of various bioactive components which includes alkaloids, flavonoids, phenols, tannins, saponins, steroids and carbohydrates. The free radical scavenging ability in the methanolic extract of the rhizome revealed significant scavenging activity by percentage inhibition in a dose dependent manner when compared with standard ascorbic acid. Observing these studies, it can be concluded that the methanolic extract of $Z$. officinale rhizome could be used in drug formulation because of its effective antioxidant properties.
\end{abstract}

\section{Introduction}

Natural products derived from plants have been used to help mankind sustain human health since the dawn of medicine. Plant derived medicinal products have attracted many scientists around the world for many years due to their minimum side effects and positive effects on human health (Aye et al., 2019). Medicinal plants are generally known as "chemical goldmines" as they contain natural chemicals which are acceptable to human and animal systems (Dhanik et al., 2017). Demand for more and more drugs from plant sources is increasing and there is a need to screen medicinal plants for promising biological activities (Laboni et al., 2016). Different types of secondary metabolites found in the medicinal plants are used for manufacturing medicines. These secondary metabolites protect the cells from the damage, caused by unstable molecules, known as free radicals (Harini and Nithyalakshmi, 2017). The free radicals may be either oxygen derived (ROS) or nitrogen derived (RNS) (Kumar et al., 2012). The most common reactive oxygen species include superoxide anion $\left(\mathrm{O}_{2}\right)$, hydrogen peroxide $\left(\mathrm{H}_{2} \mathrm{O}_{2}\right)$, peroxyl radicals (ROO) and reactive hydroxyl radicals $(\mathrm{OH})$. The nitrogen derived free radicals are nitric oxide $(\mathrm{NO})$, peroxy nitrite

Corresponding author: Ms. P. Manju

Associate Professor, Department of Biochemistry, Rathnavel Subramaniam College of Arts and Science, Coimbatore-641402, Tamil Nadu, India. E-mail: manju.palanivelu@gmail.com

Tel.: +91-9629975854 anion (ONOO), nitrogen dioxide $\left(\mathrm{NO}_{2}\right)$ and dinitrogen trioxide $\left(\mathrm{N}_{2} \mathrm{O}_{3}\right)$. Chemical compounds and reactions capable of generating free radicals are referred to as 'pro-oxidants'. Antioxidants greatly reduce the damage caused by free radicals before they attack the cells and prevent damage to lipids, proteins, enzymes, carbohydrates and DNA (Kumar and Pandey, 2015). Disruption of the balance between ROS and antioxidant system can result in oxidative stress that plays an important role in the pathophysiology of many diseases (Vinaykumar, 2015). Herbal antioxidants have been successfully employed as rejuvenators, for several centuries in the Indian systems of alternative medicine (Gupta et al., 2006).

Phytochemicals have the ability to perform various biological functions like reducing oxidative stress and degenerative ailments (Manach et al., 2004). Polyphenols and flavanoids are secondary metabolites in plants that take part in chemical reactions as reducing agents and have metal chelating potential (Atoiu et al., 2005). Spices are indispensable item of every household. Though, spices have nutritive value they are required in small amounts to add essence and fragrance to food. Plant parts which have been used either as flavouring agent or to synthesize drugs can be root, leaf, fruit, flower, seeds or the whole plant to maintain health and to treat the diseases (Alam, 2019).

Ginger is a spice and medicinal plant belonging to the Zingiberaceae family. It has long been used in folk medicine in India and China (Jabborova et al., 2020). It is a rich source of secondary metabolites such as phenolic compounds (gingerol, paradol and shagaols), volatile sesquiterpenes (Zingiberene and Bisabolene) and

Copyright (C) 2020 Ukaaz Publications. All rights reserved.

Email: ukaaz@yahoo.com; Website: www.ukaazpublications.com 
monoterpenoids (Curcumane and citral) (Ali et al., 2008). Ginger has a long history of use in Chinese and Ayurvedic medicine as an antioxidant, antipyretic, gastroprotective, antitussive. antiemetic and as hepatoprotective agent (Bhandari and Sethiya, 2018). Based on the traditional uses and pharmacological properties of rhizome of $Z$. officinale, the present study was conducted to screen the phytochemical compounds in the aqueous, methanol, diethyl ether and chloroform extracts and to evaluate the free radical scavenging efficacy in the methanolic extract of $Z$. officinale.

\section{Materials and Methods}

\subsection{Collection of sample and extraction of bioactive compound}

The rhizome of Zingiber officinale Rosc. was collected from the market of Coimbatore, India. The collected plant rhizome was authenticated by the Botanical Survey of India. Coimbatore (BSI/ $\mathrm{SRC} / 5 / 23 / 2015 / \mathrm{TECH} / 2088$ ). The selected rhizome sample was washed thoroughly with distilled water twice and shade dried at room temperature for 3 days (Hoque et al., 2013). Then, about $200 \mathrm{~g}$ of dried rhizome was ground into fine powder and was stored in separate sterile, polythene bags. $10 \%$ of polar and nonpolar extracts were prepared with powdered sample. For the preparation of extracts, $10 \mathrm{~g}$ of powdered sample was added each to $100 \mathrm{ml}$ of water, methanol, diethyl ether and chloroform and the containers were incubated at $40^{\circ} \mathrm{C}$ for $24 \mathrm{~h}$ in shaking incubator at $60-70 \mathrm{rpm}$. After incubation, the extracts again heated at $40^{\circ} \mathrm{C}$ in water bath to get effective results (Choudari and Kareppa, 2013). The extracts were filtered with Whatman No. 1 filter paper and the solvent was evaporated in a rotary evaporator. The dried extracts were used for phytochemical analysis and for evaluation of free radical scavenging activity. One $\mathrm{mg}$ per $\mathrm{ml}$ was prepared by dissolving $100 \mathrm{mg}$ extract in $100 \mathrm{ml}$ of water. This was used as sample solution for further studies.

\subsection{Phytochemical analysis}

Phytochemical tests were performed according to the standard methods (Raaman, 2006) to detect the major phytochemicals like alkaloids, flavonoids, phenols, steroids, etc., in the polar and nonpolar solvent extracts of $Z$. officinale.

\subsection{Analysis of antioxidant activity of methanolic extracts of Z. officinale (ZoMe)}

\subsubsection{DPPH assay}

The free radical scavenging activity of ZoMe was based on the scavenging activity of the stable 1,1-Diphenyl-2-Picrylhydrazyl (DPPH) free radical (Mensor et al., 2001). To $0.5 \mathrm{ml}$ of $0.3 \mathrm{mM}$ DPPH solution in methanol was mixed with $5 \mu$ l of ZoMe solutions of varying concentrations. The mixture was allowed to stand at room temperature for $30 \mathrm{~min}$ in dark. DPPH methanol solution was used as positive control and corresponding blank sample was prepared. Standard L-ascorbic acid of variying concentrations was taken. After incubation, the conversion of purple colour to yellow colour was read at $518 \mathrm{~nm}$. The percentage inhibition was calculated using the formula given below:

$$
\text { Inhibition } \%=(\text { Ac-As }) / A c \times 100
$$

where, Ac is the absorbance of the control and As is the absorbance of the sample.

\subsubsection{Superoxide radical scavenging assay}

The assay tubes contained test sample with $0.2 \mathrm{ml}$ of EDTA, $0.1 \mathrm{ml}$ NBT, $0.05 \mathrm{ml}$ riboflavin and $2.55 \mathrm{ml}$ of phosphate buffer. The control tubes were also set up where DMSO was added instead of sample (Winterbourn et al., 1975). The initial optical density of the solution was recorded at $560 \mathrm{~nm}$. After that, these tubes were placed in an area where they received uniform illumination for $30 \mathrm{~min}$. Again, the optical density was measured at $560 \mathrm{~nm}$. The difference in optical density before and after illumination is the quantum of superoxide production and the percentage of inhibition by the test sample was calculated by comparing with optical density of the control. The percentage inhibition was calculated by the following formula:

Superoxide Scavenging activity $(\%)=$ A (After illumination)-A (Before illumination)/A (control) X 100

\subsubsection{Nitric oxide scavenging activity}

Three $\mathrm{ml}$ of reaction mixture containing sodium nitroprusside in phosphate buffered saline and the extract was incubated at $25^{\circ} \mathrm{C}$ for $30 \mathrm{~min}$. After incubation, $0.5 \mathrm{ml}$ of griess reagent was added and allowed to stand for $30 \mathrm{~min}$. The absorbance of the chromophore formed, was read at $546 \mathrm{~nm}$ (Ruch et al., 1989). The percentage inhibition of nitric oxide generation was measured by comparing the absorbance values of control (Ac) and those of test compounds (As).

Nitric oxide scavenging activity $(\%)=($ Ac-As $) /$ Ac x 100

\subsubsection{Hydrogen peroxide scavenging assay}

A solution of $\mathrm{H}_{2} \mathrm{O}_{2}(40 \mathrm{mM})$ was prepared in phosphate buffer. Rhizome extract (ZoMe) at a concentration of $10 \mathrm{mg}$ in $10 \mu \mathrm{l}$ were added to $\mathrm{H}_{2} \mathrm{O}_{2}$ solution $(0.6 \mathrm{ml})$ and the total volume was made up to $3 \mathrm{ml}$. The absorbance of the reaction mixture was recorded at $230 \mathrm{~nm}$ in a spectrophotometer. A blank solution $\left(\mathrm{A}_{0}\right)$ containing phosphate buffer, without $\mathrm{H}_{2} \mathrm{O}_{2}$ was prepared (Green and Hill, 1984)

The extent of $\mathrm{H}_{2} \mathrm{O}_{2}$ scavenging of the plant extracts $\left(\mathrm{A}_{1}\right)$ was calculated as:

$$
\mathrm{H}_{2} \mathrm{O}_{2} \text { scavenging activity }(\%)=\left(\mathrm{A}_{0}-\mathrm{A}_{1}\right) / \mathrm{A}_{0} \mathrm{x} 100
$$

\subsection{Statistical analysis}

The results of in vitro free radical scavenging activity by DPPH, super oxide, nitric oxide and hydrogen peroxide were expressed as mean $\pm \mathrm{SD}$. Linear Regression was done to calculate the $\mathrm{IC}_{50}$ (half maximal inhibitory concentration) values.

\section{Results}

\subsection{Phytochemical analysis}

Phytochemical screening was done to determine the presence or absence of bioactive compounds in the polar and nonploar extracts of $Z$. officinale. Methanolic extract of the rhizome showed the presence of numerous phytoconstituents such as alkaloids, flavonoids, phenols, tannins, saponins, carbohy drates and steroids whereas, quinones, proteins and aminoacids were absent (Table 1). Since methanolic extract of $Z$. officinale showed the presence of maximum number of phytoconstituents, it was used for in vitro free radical scavenging assay. 
Table 1: Qualitative analysis of phytochemicals in different solvent extracts of $Z$. officinale

\begin{tabular}{|c|c|c|c|c|c|}
\hline \multirow[b]{2}{*}{ S.No. } & \multirow[b]{2}{*}{ Phytochemicals } & \multicolumn{4}{|c|}{$\begin{array}{l}\text { Phytochemicals in solvent } \\
\text { extracts of } Z \text {. officinale }\end{array}$} \\
\hline & & $\underset{\Xi}{ٍ}$ & 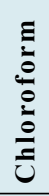 & $\frac{\vdots}{\stackrel{0}{0}}$ & 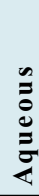 \\
\hline 1 & Alkaloids & + & + & - & + \\
\hline 2 & Carbohydrates & + & - & - & - \\
\hline 3 & Flavonoids & + & + & + & + \\
\hline 4 & Free amino acid & - & - & - & - \\
\hline 5 & Phenols & + & - & - & - \\
\hline 6 & Proteins & - & - & - & - \\
\hline 7 & Quinones & - & - & + & - \\
\hline 8 & Saponins & + & - & - & + \\
\hline 9 & Steroids & + & - & - & - \\
\hline 10 & Tannins & + & - & - & - \\
\hline
\end{tabular}

Keynote: $(+)$ : Present, (-): absent.

\subsection{Determination of DPPH radical scavenging activity}

The methanolic extract of $Z$. officinale (ZoMe) was analysed for DPPH scavenging ability and the values are presented in Table 2 . The ZoMe had marked scavenging effect on the DPPH radicals. The scavenging activity of the extract increases with increasing concentration in the range of 20 to $100 \mu \mathrm{g} / \mathrm{ml}$ and the maximum effect was observed at a concentration of $100 \mu \mathrm{g} / \mathrm{ml}$. Maximum percent inhibition exhibited by ZoMe was $31.22 \%$, whereas standard ascorbic acid showed the scavenging activities of $41.63 \%$ on the DPPH radical. Ascorbic acid used as positive control and exhibited a pronounced DPPH scavenging activity than the rhizome extract. Scavenging activity is associated with lower $\mathrm{IC}_{50}$ values as the $\mathrm{IC}_{50}$ value of ascorbic acid was lesser (117.60) than the ZoMe (174.15).

\subsection{Super oxide radical scavenging}

The scavenging activity of the ZoMe against superoxide radical is shown in Table 2. From the results, it may be postulated that the ZoMe was able to reduce the superoxide radical in a concentration dependent manner. The percentage inhibition of superoxide anion radical generated at $100 \mu \mathrm{g} / \mathrm{ml}$ of the extract was found to be $32.56 \%$ on the other hand ascorbic acid exhibited $41.54 \%$. The $\mathrm{IC}_{50}$ values of ZoMe was found to be 152.57 comparable with the standard ascorbic acid 121.11.

\subsection{Nitric oxide radical scavenging}

Nitric oxide radical scavenging activity of ZoMe was concentration dependent, as the concentration of the test compounds increases, the radical scavenging activity also increases as shown in Table 2. The nitric oxide scavenging ability of the methanolic extract was found to be $35.78 \%$ at $100 \mu \mathrm{g} / \mathrm{ml}$. This was compared with the standard antioxidant ascorbic acid possessing $48.39 \%$ at the same concentration. The ability to scavenge $50 \%$ of nitric oxide radical by ZoMe was found to be 146.61 comparable to the reference standard ascorbic acid 98.90 .

\subsection{Hydrogen peroxide assay}

The ability of ZoMe to scavenge $\mathrm{H}_{2} \mathrm{O}_{2}$ was evaluated and the findings are shown in Table 2.

The methanolic extract of $Z$. officinale exerted a good hydrogen peroxide scavenging activity. Percentage inhibition of the free radicals was directly proportional to the concentration of the rhizome extract. The methanolic extract of $Z$. offiicinale exhibited $34.38 \%$ inhibition and the ascorbic acid showed $49.63 \%$ at $100 \mu \mathrm{g} /$ $\mathrm{ml}$. The percentage of inhibition of ZoMe showed an $\mathrm{IC}_{50}$ value of 160.95 as compared to the standard ascorbic acid of 99.24 . Thus, the findings revealed that the rhizome extract was capable of scavenging the hydrogen peroxide in a concentration dependent manner.

Table 2: Free radical scavenging activity of $Z$. officinale (ZoMe)

\begin{tabular}{|c|c|c|c|c|c|c|c|c|c|}
\hline \multirow[t]{2}{*}{ Sample } & \multirow{2}{*}{$\begin{array}{l}\text { Concentration } \\
(\mu \mathrm{g} / \mathrm{ml})\end{array}$} & \multicolumn{2}{|l|}{ DPPH } & \multicolumn{2}{|l|}{ Superoxide } & \multicolumn{2}{|l|}{ Nitric Oxide } & \multicolumn{2}{|c|}{ Hydrogen peroxide } \\
\hline & & $\%$ Inhibition & $\mathrm{IC}_{50}$ & $\%$ Inhibition & $\mathrm{IC}_{50}$ & $\%$ Inhibition & $\mathrm{IC}_{50}$ & $\%$ Inhibition & $\mathrm{IC}_{50}$ \\
\hline ZoMe & $\begin{array}{l}20 \\
40 \\
60 \\
80 \\
100 \\
\end{array}$ & $\begin{array}{l}12.46 \pm 0.32 \\
17.42 \pm 0.23 \\
21.55 \pm 0.21 \\
28.54 \pm 0.34 \\
31.22 \pm 0.28\end{array}$ & 174.15 & $\begin{array}{l}8.25 \pm 0.09 \\
15.65 \pm 0.32 \\
21.67 \pm 0.22 \\
28.82 \pm 0.16 \\
32.56 \pm 0.22\end{array}$ & 152.57 & $\begin{array}{l}9.46 \pm 0.18 \\
11.57 \pm 0.13 \\
19.32 \pm 0.14 \\
26.82 \pm 0.13 \\
35.78 \pm 0.21\end{array}$ & 146.61 & $\begin{array}{l}12.51 \pm 0.22 \\
17.31 \pm 0.16 \\
21.59 \pm 0.18 \\
27.66 \pm 0.32 \\
34.38 \pm 0.23\end{array}$ & 160.95 \\
\hline $\begin{array}{l}\text { Ascorbic } \\
\text { acid }\end{array}$ & $\begin{array}{l}20 \\
40 \\
60 \\
80 \\
100\end{array}$ & $\begin{array}{l}10.22 \pm 0.09 \\
15.26 \pm 0.12 \\
24.69 \pm 0.17 \\
36.76 \pm 0.21 \\
41.63 \pm 0.27\end{array}$ & 117.60 & $\begin{array}{l}10.38 \pm 0.17 \\
18.47 \pm 0.21 \\
25.77 \pm 0.20 \\
34.35 \pm 0.21 \\
41.54 \pm 0.21\end{array}$ & 121.11 & $\begin{array}{l}15.55 \pm 0.30 \\
27.41 \pm 0.28 \\
35.63 \pm 0.28 \\
43.49 \pm 0.28 \\
48.39 \pm 0.27\end{array}$ & 98.90 & $\begin{array}{l}13.63 \pm 0.22 \\
19.55 \pm 0.22 \\
31.63 \pm 0.38 \\
42.45 \pm 0.33 \\
49.63 \pm 0.23\end{array}$ & 99.24 \\
\hline
\end{tabular}

\section{Discussion}

Ginger has rich phytochemistry and have been used in the treatment of various disorders including cancer due to its anti-inflammatory and antioxidant properties (Al-Awwadi, 2017). The biological active components present in ginger such as polyphenols, flavonoids contain anticancer, antiviral and antihypertensive properties (Shoaib et al., 2016). In the present study, the methanolic extract of $Z$. officinale (ZoMe) showed the presence of phytochemicals such as flavonoids, polyphenols and alkaloids. Concurrent findings have been reported by Shalini and Pushpa (2013) who indicated the presence of carbohydrates, proteins, phenols, tannins, volatile oils, steroids, saponins, alkaloids and flavonoids in the aqueous and ethanolic extracts of Murraya koenigii. Phytochemical screening affirmed the presence of alkaloids, flavonoids and tannins in the methanolic extract of Colocasia affinis schott (Mondal et al., 2019). Modi et al. (2018) observed the presence of alkaloids, saponins, tannins and several polyphenols in the methanolic extracts of leaves of Abrus precatorius. 
Phytochemical constituents in plants are the rich source of antioxidants having free radical scavenging property (Umesh et al., 2015). DPPH is a stable free radical at room temperature and accept an electron or hydrogen radicals to become a stable diamagnetic molecule. The free radical scavenging ability of methanolic extract of $Z$. officinale and ascorbic acid was evaluated through its ability to quench the synthetic DPPH potential and showed that percentage of inhibition increased in a dose dependent manner. Similar findings were observed in the methanolic extract of several medicinal plants and showed significant levels of radical scavenging activity in a dose dependent manner (Rezaeian et al., 2015). Concurrent findings were observed in the crude methanol extracts of Gymnosporia montana (Ansari and Chandel, 2019). The crude methanolic extract of Drynaria quercifolia rhizome exhibited noticeable free radical scavenging activity (Chaity et al., 2016). Methanolic extract of Aprosa wallichi exhibited strong DPPH activity with $\mathrm{IC}_{50}$ value of $75.6 \mu \mathrm{g} / \mathrm{ml}$ (Sharmin et al., 2018). They also indicated that presence of DPPH free radical scavenging activity specifies the presence of antioxidants in Aprosa wallichi. Thus, these findings supports the DPPH radical scavenging ability of $Z$. officinale.

Superoxide radicals are considered as primary ROS and can produce secondary ROS through interaction with other molecules directly or indirectly through enzymic or enzyme catalyzed reactions (Ifeanyi, 2018). The results of the present study revealed that the percentage of inhibition of superoxide was found to be maximum at a higher concentration of $100 \mu \mathrm{g} / \mathrm{ml}$ by ZoMe and their activities are comparable to that of the ascorbic acid. Dose dependent scavenging activity was reported in the methanolic extracts of root and leaves of Elephantopus scaber (Anugraha et al., 2019). Eom et al. (2020) have observed the superoxide radical scavenging activity in various solvent fractions of root extracts of Rumex crispus and indicated that solvent fractions with high flavonoid content exhibited good superoxide scavenging ability. Concurrent findings were observed by Kavitha (2014) who have reported that ethanolic extracts of leaf and fruit of Trichosanthes dioica and leaf of Clitoria ternatea where shown to have significant superoxide radical scavenging activity and it was dose dependant. Concentration dependant superoxide scavenging ability was observed in ethanolic extract of fruits of Garcinia indica (Kumar and Gurusamy, 2015). In the present study, the superoxide scavenging ability of methanolic extract of $Z$. officinale may be due to the presence of alkaloids, flavanoids and phenols.

Nitric oxide (NO) is an essential bioregulatory molecule required for several physiological processes such as neural signal transmission, immune response and cardiovascular dilation. However, elevated NO radical results in several pathological conditions and the efficiency of the plant extract to consume the nitric oxide is an effective technique for measuring the antioxidant activity (Deepak, 2019). In the present investigation, percentage of inhibition of NO was directly proportional to the concentration of ZoMe. Similar trend was indicated by Ali et al. (2015) who have reported that the chloroform extracts of Citrus hystrix leaf has potent nitric oxide scavenging activity that increased in dose dependant manner. George and Britto (2016) have also reported that the nitric oxide scavenging activity analysed in the ethanolic and acetone extracts of the rhizomes of Curcuma amada displayed a concentration dependent increase in inhibition. The metabolites of ginger have been recognized as potent antioxidants due to its ability to scavenge the nitric oxide (Semwal et al., 2015). These reports are in agreement with our study that methanolic extract of $Z$. officinale have potent nitric oxide scavenging ability.
Hydrogen peroxide was considered to be poorly reactive because of its weaker oxidising and reducing capabilities. Biologically it acts as a toxicant to the cell by converting it to hydroxyl radical in the presence of metal ions (Bakhtiar et al., 2015). In our study, the ZoMe was able to scavenge hydrogen peroxide in a concentration dependent manner. Behera (2018) determined the free radical scavenging activity of Gymnema sylvestre by hydrogen peroxide scavenging method and the whole plant extract showed concentration dependent activity. Hossain et al. (2014) have indicated that the methanolic extract of Cordia dichotoma exhibited a concentration dependent $\mathrm{H}_{2} \mathrm{O}_{2}$ scavenging capacity which peaked at $200 \mu \mathrm{g} / \mathrm{ml}$. The polyherbal formulation (Liv-Pro-08) prepared from Nigella sativa, Entada pursaetha and dried fruit of Ficus glomerata showed hydrogen peroxide scavenging activity in a dose dependant manner (Anandhi et al., 2019). Similar trend was observed in the extracts of Simarouba glauca with increase in percentage inhibition in a dose dependent manner (Lakshmi et al., 2014). Phenols and flavonoids could be the probable contributors for the antioxidative properties and inhibitory action towards the oxidative reaction in vitro and in vivo (Kasote et al., 2015).

\section{Conclusion}

Based on the results obtained in the present study, it can be concluded that the methanolic extracts of $Z$. officinale (ZoMe) were rich in phytochemicals when compared to other extracts and had the ability to scavenge almost all the radicals analysed. This may be attributed to the presence of bioactive molecules (flavonoids, alkaloids, phenols) that may serve as effective antioxidants. Thus, further research may be warranted to isolate and characterize the bioactive compounds to confer their antioxidant mechanism.

\section{Acknowledgements}

The authors wish to gratefully acknowledge Avinashilingam Institute for Home science and Higher education for Women and Rathnavel Subramaniam College of Arts and Science, Coimbatore for their generous support rendered to carry out this research work.

\section{Conflict of interest}

The authors declare that there are no conflicts of interest in the course of conducting the research. All the authors had final decision regarding the manuscript and decision to submit the findings for publication.

\section{References}

Alam, A. (2019). Herbs that heal. Spices: The hoard of natural remedies. Ann. Phytomed., 8(2):7-18.

Al-Awwadi, N.A.J. (2017). Potential health benefits and scientific review of ginger. J. Pharmacognosy Phytother., 9(7):111-116.

Ali, B.H.; Blunden, G.; Tanira, M.O. and Nammar, A. (2008). Some phytochemical, pharmacological and toxicological properties of ginger (Zingiber officinale): A review of recent research. Food Chem. Toxicol., 46:409-420.

Ali, M.; Akhter, R.; Narjish, N.; Shahriar, M. and Bhuiyan, M.A. (2015). Studies on preliminary phytochemical screening, membrane stabilizing activity, thrombolytic activity and in vitro antioxidant activity of leaf extracts of Citrus hystrix. Int. J. of Pharma Sci. and Res., 6(16):2367-2374. 
Anandhi, E.; Suriyavathaa, M.; Kavitha, R.M. and Punithavathi. M. (2019). Phytochemical analysis and free radical scavenging activity of green synthesized (Liv-Pro-08) formulation, RJLBPLS, 5(1):613625 .

Ansari, N. and Chandel, D. (2019). Antioxidant studies on Methanol and Aqueous extracts of Gymnosporia montana. Plant Int. J. Pharm. and Pharm. Sci., 11(2):65-70.

Anugraha, S.; Vennila, L.; Asaikumar, L.; Vijayakumar, N.; Panbilnathan, A.; Krishnan, A. and Arya, R. (2019). In vitro antioxidant activity of methanolic leaf and root extracts of Elephantopus scaber. J. Pharmacog. and Phytochem., 8(3):404-412.

Atoui, A.K.; Mansouri, A.; Boskou, G. and Kefala, P. (2005). Tea and herba infusions: Their antioxidant activity and phenolic profile. Food Chem., 89:27-36.

Aye. M.M.; Aung, H.T.; Sein, M.M. and Armijos, C.A. (2019). A review on the phytochemistry, medicinal properties and pharmacological activities of 15 selected myanmar medicinal plants. Mol., 24:293.

Bakhtiar, M.S.I.; Shahriar, M.; Akhter. R. and Bhuiyan, M.A. (2015). In vitro antioxidant activities of the whole plant extract of Chrozophora prostrata (dalz.). Ann. Biol. Res., 6(4):19-26.

Behera, S.K. (2018). Phytochemical screening and antioxidant activities of Gymnema sylvestr. Free Radicals and Antioxidants, 9(1):12-15.

Bhandari, R. and Sethiya. J.P. (2018). A pharmacological investigation of Zingiber officinale. Int. J. Res. and Rev., 5(10):465-469.

Chaity, F.R; Khatun. M. and Rahman M.S. (2016). In vitro membrane stabilizing, thrombolytic and antioxidant potentials of Drynaria quercifolia L., a remedial plant of the Garo tribal people of Bangladesh. BMC Complem and Altern. M., 16:184.

Choudhari, S.S. and Kareppa, B.M. (2013). Identification of bioactive compounds of Zingiber officinale roscoe rhizomes through gas chromatography and mass spectrometry. International Journal of Pharmaceutical Research and Development, 5(08):016-020.

Deepak, M.; Sulaiman, C.T.; Balachandran, I. and Subashchandran K.P. (2019) Antioxidant activity guided isolation of chemical constituents from whole plant of Canscora perfoliata. IJPPR, 11(3):129-134.

Dhanik, J.; Arya, N. and Nand, V. (2017). A review on Zingiber officinale. J. Pharmacog. and Phytochem., 6(3):174-184.

Eom, T.; Kim. E. and Kim. J.S. (2020). In vitro antioxidant, anti-inflammation and anticancer activities and anthraquinone content from Rumex crispus root extract and fractions. Antioxidants, 9,726:1-13.

George, M. and Britto, J. (2016). Phytochemical, antioxidant and antibacterial studies on the leaf extracts of Curcuma amada Roxb. Int. J. Curr. Pharm Res., 8(2):32-38

Green, M.J. and Hill, H.A. (1984). Chemistry of dioxygen methods. Enzymol., 105:3-22.

Gupta, S.; Shukla, R. and Sharma, K.K. (2006). Anti-hypercholesterolemic and antioxidant effect of Ocimum sanctum (Linn) seed oil. Ind. Jr. Exp. Biol., 44(4):300-303.

Harini, K. and Nithyalakshmi, V. (2017). Phytochemical analysis and antioxidant potential of Cucumis melo seeds. Int. J. of Lif. Sci. Res., 3(1):863-867.

Hoque, M.A.; Bala, B.K.; Hossain, M.A and Uddin, M.B. (2013). Drying kinetics of ginger rhizome (Zingiber officinale). Bangladesh. J. Agril. Res., 38(2):301-319.
Hossian, N.; Kakoti, B.B. and Alok, S. (2014). In vitro antioxidant activity of methanolic extract of bark of Cordia dichotoma Forst. Int. J. of Pharma Sci. and Res., 5(1):142-147.

Ifeanyi, O.E. (2018). A review on free radicals and antioxidants. Int. J. Curr. Res. Med. Sci., 4(2):123-133.

Jabborova, D.; Annapurna. K.; Fayzullaeva, M.; Sulaymonov. K. and Kadirova. D. (2020). Isolation and characterization of endophytic bacteria from ginger (Zingiber officinale). Ann. Phytomed., 9(1):116-121.

Kasote, D.M.; Katyare, S.S.; Hedge, M.V. and Bae, H. (2015). Significance of antioxidant potential of plants and its relevance to therapeutic applications. Int. J. Biol. Sci., 11(8):982-991.

Kavitha, R. (2014). In vitro free radical scavenging activities of ethanolic extract of leaf and fruit of Trichosanthes dioica. Int. J. Pharm Sci. Rev. Res., 27(1),Article No.54:298-303.

Kumar, S.; Sharma, U.K.; Sharma, A.K. and Pandey, A.K. (2012). Protective efficiency of Solanum xanthocarpum root extracts against free radicals damage. Phytochemical analysis and antioxidant effect. Cell Mol. Biol., 58:171-178.

Kumar, S. and Pandey, A.K. (2015). Free radicals: Health implication and their mitigation by herbals. British Journal of Medicine and Medical Research., 7(6):438-457.

Kumar, V.D.R. and Gurusamy, K. (2015). Antioxidant and free radical scavenging potential of ethanolic extract of Garcinia indica Linn. fruits. IJSR, 4(4):9-13.

Laboni, F.R.; Batul, U.K.; Islam, S.; Hossain, P.; Rahman, M.D.M. and Uddain, J. (2016). Phytochemical screening, antibacterial, thrombolytic and anti-inflammatory activities of stem and root extracts of Basak, Adhatoda vasica. WJSE, 1(1):55-63.

Lakshmi, K.S.; Sangeetha, D.; Sivamani, S.; Tamilselvan, M.; Rajesh, T.P. and Anandaraj, B. (2014). In vitro antibacterial, antioxidant, hemolytic, thrombolytic activities and phytochemical analysis of Simarouba glauca extracts. Int. J. of Pharma Sci. and Res., 5(2):432-437.

Manach, C.; Scalbert, A.; Morand, C.; Remesy, C. and Jimenez, L. (2004). Polyphenols: Food sources and bioavailability. Am. J. Clin. Nutr., 79:727-747.

Mensor, L.I.; Menezes, F.S.; Leitao, G.G.; Reis, A.S. and Santos, T. (2001). Screening of Brazilian plant extracts for antioxidants activity by the use of DPPH free radical method. Phytother. Res., 15:127-130.

Modi, C.M.; Ledumor, C.V.; Patel. D.V.; Harshad, B. and Patel, B.H. (2018). Phytochemical analysis and comparative study of in vitro free radical scavenging activity of different extracts of leaves of Abrus precatorious L. Ann. Phytomed., 7(2):133-137.

Mondal, M.; Hossain, M.S. and Das, N. (2019). Phytochemical screening and evaluation of pharmacological activity of leaf methanolic extract of Colocasia affinis schott. Clin. Phytosci., 5:8.

Raaman, N. (2006). Phytochemical agency (Techniques), New India Publishing agency, New Delhi., 19(24):32-40.

Rezaeian, S.; Pourianfar, H.R. and Janpoor, J. (2015). Antioxidant properties of several medicinal plants growing wild in northeastern Iran. Asian J. Plant Sci. Res., 5(2):63-68.

Ruch, R.J.; Cheng, S.J. and Klaunig, J.E. (1989). Prevention of cytotoxicity and inhibition of intercellular communication by antioxidant catechins isolated from Chinese green tea. Carcinogenesis, 10(6): 1003-1008 
Semwal, R.B.; Semwal, D.K.; Combrin, K.S. and Viljoen, A.M. (2015). Gingerols and shaogols: Important nutraceutical principles from ginger. Phytochem., 117:554-558.

Shalini, R. and Pushpa, A. (2013). A study on the cytotoxic and antioxidative potential of Murraya koenigii. Int. J. Pharm. Sci. Rev. Res., 16:98-100.

Sharmin, S.; Kabir, M.T.; Islam, M.N.; Jamiruddin, M.R.; Rahman, I.; Rahman, A. and Hossain, M. (2018). Evaluation of antioxidant, thrombolytic and cytotoxic potential of methanolic extract of Aprosa wallichi Hook f.leaves: An unexplored phytomedicine. J. Appl. Pharm. Sci., 8(07):051-056.
Shoaib, M.; Shehzad, A.; Butt, M.S.; Saeed, M.; Raza, H.; Niazi, S.; Khan, I.M. and Shakeel, A. (2016). An overview: Ginger, a tremendous herb. J. Glb. Innov. Agric. Scc. Sci., 4(4):172-187.

Umesh, T.G. (2015). In vitro antioxidant potential, free radical scavenging and cytotoxic activity of Simarouba gluaca leaves. Int. Pharm. Pharm. Sci., 7(2):411-416.

Vinay Kumar, U.K.B.; Khan, A.A.; Tripathi, A.; Dixit, P.K. and Bajaj, U.K. (2015). Role of oxidative stress in various diseases. Relavance of dietary antioxidants. The Journal of Phytopharmacology, 4(2):126-132.

Winterbourn, C.; Hawlans, R.E.; Brain, M. and Cavell, R.W. (1975). The estimation of Red cell, superoxide dismutase activity. J. Lab. Clin. Med., 85:337-341.

Citation P. Manju and A. Pushpa (2020). Phytochemical analysis and in vitro free radical scavenging activity of rhizome of Zingiber officinale Rosc. Ann. Phytome d., 9(2):257-262. http://dx.doi.org/10.21276/ap.2020.9.2.24 